\title{
Assessment of efficiency and safety of adenovirus mediated gene transfer into normal and damaged murine livers
}

T Nakatani, S Kuriyama, K Tominaga, T Tsujimoto, A Mitoro, M Yamazaki, $\mathrm{H}$ Tsujinoue, H Yoshiji, S Nagao, H Fukui

\begin{abstract}
Background-When recombinant adenoviruses are infused directly into the circulation, transgene expression is almost completely restricted to the liver. Aims-Efficiency and safety of adenovirus mediated gene transfer into damaged livers were examined in mice with liver cirrhosis or fulminant hepatitis.

Methods-Liver cirrhosis and fulminant hepatitis were induced by intraperitoneal administration of thioacetamide and D-galactosamine followed by lipopolysaccharide, respectively. Mice were infused with adenoviruses carrying the Escherichia coli $\beta$-galactosidase gene, lac $Z$ gene, into the tail vein. Transduction efficiency of the $l a c Z$ gene was estimated histochemically by X-gal staining and quantitatively using a chemiluminescent assay. Activation of adenovirus specific $T$ cells and development of neutralising antibodies against adenovirus were also examined.
\end{abstract}

Results-Histochemical evaluation revealed that approximately $40 \%, 80 \%$, and $40 \%$ of cells in normal, cirrhotic, and fulminant hepatitis livers, respectively, were stained blue using X-gal staining. Quantitative analyses revealed that levels of lacZ expression in cirrhotic livers were approximately 2.5 -fold and sixfold greater than those in normal and fulminant hepatitis livers, respectively. Although transgene expression in fulminant hepatitis livers was significantly lower than that in normal livers, marked levels of transgene expression were achieved even in fulminant hepatitis livers. Significant adverse effects of adenoviruses were not observed in damaged livers. There were no significant differences in cellular or humoral immune responses to adenoviruses among animals with normal, cirrhotic, and fulminant hepatitis livers.

Conclusions-Our results suggest that gene therapy with adenoviruses may be used efficiently and safely, even in patients with severe liver disease. (Gut 2000;47:563-570)

Keywords: adenovirus; transduction efficiency; safety; liver cirrhosis; fulminant hepatitis

Recently, intensive efforts have been made towards developing practical strategies for gene therapy against a variety of diseases. In vivo gene therapy is more practical than ex vivo therapy because the latter requires invasive surgical procedures to collect target cells for genetic modification. Adenoviruses are ideally suited for in vivo gene therapy because of their high titres and ability to mediate a high level of transgene expression in a wide variety of cells and tissues. Adenovirus serotypes 2 and 5, which cause respiratory diseases in humans, have been developed for use in gene therapy; both belong to subgroup $\mathrm{C}$ adenoviruses which are not associated with human malignancies. ${ }^{1}$ The natural tropism of adenoviruses for airway epithelia has been exploited in the development of gene therapy for cystic fibrosis. ${ }^{2-4}$ Another application of recombinant adenoviruses, which is different from the usual spectrum of naturally acquired infections, is in liver directed gene therapy. Recombinant adenoviruses infused directly into the circulation primarily target hepatocytes. ${ }^{5-9}$ Hence in vivo gene transfer into the liver using adenoviral vectors are promising gene therapy strategies. Furthermore, the use of hepatocyte specific promoters, such as the albumin gene promoter, may provide more restricted transgene expression in hepatocytes. ${ }^{1011}$

Despite these advances, several factors significantly limit the use of current early gene region 1 (E1) deleted adenoviral vectors. Cellular and humoral immune responses directed against the virus and transgene encoded proteins, which results in transient gene expression, and inability to readminister vectors of the same serotype have been described. ${ }^{12}$ Furthermore, hepatotropic transgene expression induced by adenoviral vectors results in hepatic injury. ${ }^{13}$ Therefore, it is important to estimate the efficiency and safety of adenovirus mediated gene transfer into damaged livers because it is possible that patients with liver diseases may undergo gene therapy in the future. However, these issues remain to be examined.

In the present study, we investigated liver cirrhosis and fulminant hepatitis as these are the most serious of the various liver diseases. We estimated efficiency of adenovirus medi-

Abbreviations used in this paper: E1, early gene region 1; pfu, plaque forming units; LPS, lipopolysaccharide; TAA, thioacetamide; GalN, D-galactosamine; ALT, alanine aminotransferase; AST, aspartate aminotransferase; $\mathrm{LDH}$, lactate dehydrogenase; BUN, blood urea nitrogen; DMEM, Dulbecco's modified Eagle's medium; HCC, hepatocellular carcinoma. 
ated transfer of a reporter gene into mice with cirrhosis of the liver or fulminant hepatitis. We also examined the cytopathic effects of adenoviruses to estimate the safety of adenoviral administration into animals with severely damaged livers.

\section{Methods}

ADENOVIRAL VECTOR

Adex1CAlacZ adenovirus was generously provided by Dr Izumu Saito (Institute of Medical Science, University of Tokyo, Tokyo, Japan) and details of the construction procedures have been described previously. ${ }^{14}$ This adenovirus vector carries an adenovirus serotype 5 genome lacking the $\mathrm{E} 1 \mathrm{~A}$ and $\mathrm{E} 1 \mathrm{~B}$ regions to prevent virus replication, and contains the Escherichia coli $\beta$-galactosidase gene, lac $Z$ gene, as a reporter gene between the CAG promoter composed of the cytomegalovirus enhancer plus the chicken $\beta$-actin promoter ${ }^{15}$ and the rabbit $\beta$-globin polyadenylation signal in place of the $\mathrm{E} 1 \mathrm{~A}$ and $\mathrm{E} 1 \mathrm{~B}$ regions. This adenovirus vector also lacks the $\mathrm{E} 3$ region to make space for exogenous DNA. Although deletion of the E3 region has no role in preventing adenoviral DNA replication, its absence could affect the severity of viral cytopathic effects and immune responses. The recombinant adenovirus was propagated and isolated in 293 cells, as described previously. ${ }^{16}$ The viral solution was stored at $-150^{\circ} \mathrm{C}$ until use. To titre the viral solution, an aliquot of virus was serially diluted and assayed for ability to form plaques on 293 cell monolayers, as described previously. ${ }^{17} \mathrm{~A}$ single batch of high titre adenovirus stock $\left(1 \times 10^{9}\right.$ plaque forming units $\left.(\mathrm{pfu}) / \mathrm{ml}\right)$ was used for subsequent experiments.

ANIMALS AND TREATMENT

Eight week old female BALB/c mice, weighing 20-22 g, were purchased from Japan SLC Inc (Hamamatsu, Japan), supplied with food and water ad libitum, and exposed to a 12 hour light-dark cycle at a constant room temperature of $24(2)^{\circ} \mathrm{C}$. D-Galactosamine (GalN) is an amino sugar selectively metabolised by hepatocytes which induces depletion of the uridine triphosphate pool and thereby inhibition of macromolecule synthesis, such as RNA, proteins, and glycogen in the liver. ${ }^{18}$ When given together with a low dose of lipopolysaccharide (LPS), GalN sensitises animals to cause acute severe hepatotoxicity resulting in the development of fulminant hepatitis. ${ }^{19}{ }^{20}$ In contrast, intraperitoneal administration of thioacetamide (TAA) to mice is known to cause liver cirrhosis, characterised by hepatocellular necrosis, increased connective tissue, and formation of regenerative nodules.

For the fulminant hepatitis model, mice were injected intraperitoneally with a necrotic dose of GalN (Nacalai Tesque, Kyoto, Japan) (500 $\mathrm{mg} / \mathrm{kg}$ body weight) followed by an intraperitoneal injection of LPS from E coli (serotype 055: B5; Sigma, St Louis, Missouri, USA) (0.1 $\mu \mathrm{g} /$ mouse) one hour later. The treatment was given to 10 week old mice. Twenty four hours later they received an intravenous infusion of adenoviruses ( $200 \mu \mathrm{l} /$ mouse) from the tail vein.
For the liver cirrhosis model, mice were given intraperitoneal injections of TAA (Nacalai Tesque) (200 mg/kg body weight) suspended in phosphate buffered saline twice weekly for 32 weeks, beginning at 10 weeks of age. They received an intravenous injection of adenoviruses $(200 \mu \mathrm{l} /$ mouse) from the tail vein seven days after termination of TAA treatment. Ten week old mice with normal livers were used as controls. Animal experiments were performed with approved protocols and in accordance with recommendations for the proper care and use of laboratory animals.

HISTOLOGICAL ANALYSIS

To histologically examine the livers of animals that received GalN and LPS, or TAA, right lateral hepatic lobes were removed from animals, fixed in $10 \%$ buffered formaldehyde, and embedded in paraffin. Livers were sliced, stained with haematoxylin-eosin or Azan, and examined under light microscopy.

IN VIVO TRANSDUCTION, X-gal STAINING, AND $\beta$-GALACTOSIDASE ACTIVITY

Mice with normal, cirrhotic, and fulminant hepatitis livers were anaesthetised with ether, and $200 \mu \mathrm{l}$ of adenovirus solution $\left(1 \times 10^{9}\right.$ $\mathrm{pfu} / \mathrm{ml}$ ) were injected into the tail vein. Animals were sacrificed four days after adenoviral injection. Each group consisted of eight animals. For histochemical staining, approximately half of the volume of the right lateral hepatic lobe from each animal was fixed with $10 \%$ buffered formaldehyde, $0.2 \%$ glutaraldehyde, and $0.02 \%$ Nonidet $\mathrm{P}-40$ in $0.1 \mathrm{M}$ sodium phosphate buffer $(\mathrm{pH} 7.4)$ for 60 minutes at room temperature. Livers were then sliced into $30 \mu \mathrm{m}$ thick sections with a microslicer (DTK3000; Dosaka EM, Kyoto, Japan). The slices were rinsed three times in phosphate buffered saline with $1 \mathrm{mM} \quad \mathrm{MgCl}_{2}$ and incubated overnight at $37^{\circ} \mathrm{C}$ in an X-gal (5-bromo-4chloro-3-indolyl- $\beta$-galactosidase; Gibco, Grand Island, New York, USA) reaction mixture to detect lac $Z$ gene expression, as described previously. ${ }^{11}$

To quantitatively measure $\beta$-galactosidase activity induced by $l a c Z$ gene expression, a chemiluminescent reporter gene assay system using Galacton-Star (Tropix, Bedford, Massachusetts, USA) was used. Briefly, approximately half of the volume of the left median hepatic lobe from each animal was homogenised in a lysis buffer consisting of $100 \mathrm{mM}$ potassium phosphate $(\mathrm{pH}$ 7.8) and $0.2 \%$ Triton X-100. Liver homogenates were centrifuged at $10000 \mathrm{rpm}$ for 10 minutes at $4^{\circ} \mathrm{C}$. Supernatants were collected, and $1 \mu \mathrm{l}$ of each supernatant sample was added to the reaction buffer containing the Galacton-Star chemiluminescent substrate. After incubation for 60 minutes at $37^{\circ} \mathrm{C}, \beta$-galactosidase activity of the supernatant samples was measured using a luminometer (TR717 Microplate luminometer; Tropix). Protein concentrations of the supernatants were measured using the Bio-Rad (Hercules, California, USA) protein assay kit with bovine serum albumin as standard. Values were standardised based on the standard curve 
of $E$ coli $\beta$-galactosidase (G-5635; Sigma) and expressed as pg of $\beta$-galactosidase $/ \mu$ g protein. Each estimation of $\beta$-galactosidase activity was performed in duplicate.

EVALUATION OF ADVERSE EFFECT BY ADENOVIRAL ADMINISTRATION

For evaluating the adverse effects of adenoviral administration, mice were subjected to thoracotomy, followed by collection of blood from the left ventricle of the heart, and serum biochemical parameters such as alanine aminotransferase (ALT), aspartate aminotransferase (AST) and lactate dehydrogenase (LDH), albumin, total bilirubin, alkaline phosphatase, choline esterase, creatinine, and blood urea nitrogen (BUN) were measured in mice treated with and without intravenous administration of adenoviruses $\left(2 \times 10^{8} \mathrm{pfu} / 200 \mu \mathrm{l}\right)$. Each group consisted of eight animals. For histological analysis of cytopathic effects caused by adenoviral administration, the left lateral hepatic lobe of each animal was removed, fixed in $10 \%$
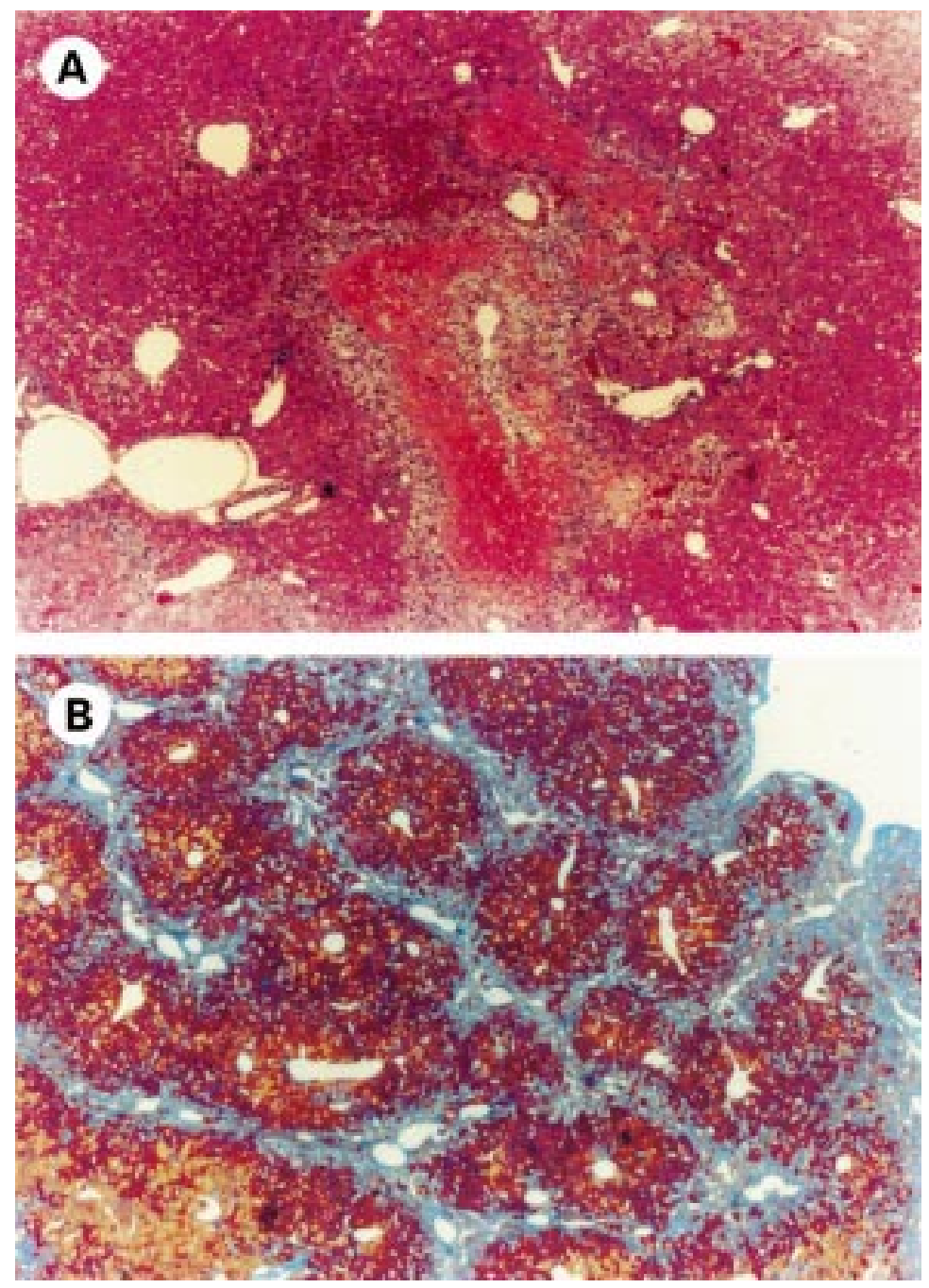

Figure 1 Histological analysis of fulminant hepatitis and liver cirrhosis models in mice. Haematoxylin-eosin staining of the liver of mice administered with D-galactosamine and lipopolysaccharide revealed acute severe hepatitis with massive haemorrhagic necrosis of hepatocytes, disarray of the lobules, and marked infiltration of inflammatory cells $(A)$. Azan staining of the liver of mice treated with thioacetamide for 32 weeks revealed an increase and thickening of the fibrotic septa, traversing the lobular parenchyma, and formation of pseudolobuli (B). (Original magnification $\times 40$.) buffered formalin, embedded in paraffin, and stained with haematoxylin-eosin.

ADENOVIRUS SPECIFIC T CELL PROLIFERATION Activation of adenovirus specific splenic $T$ cells was evaluated in a proliferation assay, as described previously. ${ }^{21} 22$ Briefly, spleen cells were collected from each animal and plated in duplicate in the wells of 96 well, flat bottomed plates $\left(5 \times 10^{5}\right.$ cells/well). Cells were incubated with medium alone (background) or stimulated with heat inactivated $\left(50^{\circ} \mathrm{C}\right.$ for 20 minutes) recombinant adenoviruses at a multiplicity of infection of 100 pfu per cell in a total volume of $250 \mu \mathrm{l}$ per well. Cells were incubated for five days at $37^{\circ} \mathrm{C} / 5 \% \mathrm{CO}_{2}$ and pulsed with $1 \mu \mathrm{Ci}$ per well $\left[{ }^{3} \mathrm{H}\right]$ thymidine (Amersham, Aylesbury, UK) for the last 18 hours of incubation. Cells were harvested onto glass fibre filters with a 96 well plate cell harvester, and cell associated radioactivity was measured by liquid scintillation counting.

NEUTRALISING ANTIBODY ASSAY

Sera were measured for neutralising antibodies against adenovirus serotype 5 as previously described. ${ }^{23}$ Briefly, murine serum samples were incubated for 30 minutes at $56^{\circ} \mathrm{C}$ to inactivate complements and diluted in Dulbecco's modified Eagle's medium (DMEM) in twofold steps starting from 1:10 dilution. Each serum dilution $(100 \mu \mathrm{l})$ was mixed with Adex $1 \mathrm{CAlacZ}$ adenoviruses $\left(2 \times 10^{6} \mathrm{pfu}\right.$ in $\left.10 \mu \mathrm{l}\right)$, incubated for 60 minutes at $37^{\circ} \mathrm{C}$, and applied to $80 \%$ confluent NIH3T3 cells in 96 well plates $\left(2 \times 10^{4}\right.$ cells per well). After a 60 minute incubation period at $37^{\circ} \mathrm{C}, 100 \mu \mathrm{l}$ of DMEM containing $20 \%$ heat inactivated fetal calf serum were added to each well. On the following day, cells were fixed and stained overnight with the $\mathrm{X}$-gal solution. All cells were stained blue in the absence of serum samples. The titre of neutralising antibody for each sample was determined to be the reciprocal dilution that inhibited $\mathrm{X}$-gal staining by $50 \%$.

STATISTICS

Results are expressed as mean (SD). Standard descriptive statistics and Welch's $t$ test were used. $\mathrm{p}<0.05$ was considered to indicate a significant difference between groups.

\section{Results}

HISTOLOGICAL ANALYSIS OF CHEMICALLY

INDUCED LIVER INJURY

When we treated mice with GalN (500 mg/kg body weight) followed by LPS $(0.1 \mu \mathrm{g} /$ mouse $)$, approximately $40 \%$ of animals died within 24 hours. Histological analysis using haematoxylin-eosin staining of the livers of mice who survived after 24 hours following GalN and LPS treatment revealed acute severe hepatitis with massive haemorrhagic necrosis of hepatocytes, disarray of the lobules, and marked infiltration of inflammatory cells, resulting in a diagnosis of fulminant hepatitis (fig 1A). Azan staining of the livers of mice treated with intraperitoneal administration of TAA ( $200 \mathrm{mg} / \mathrm{kg}$ body weight) twice weekly for 32 weeks revealed that cirrhosis was manifested 


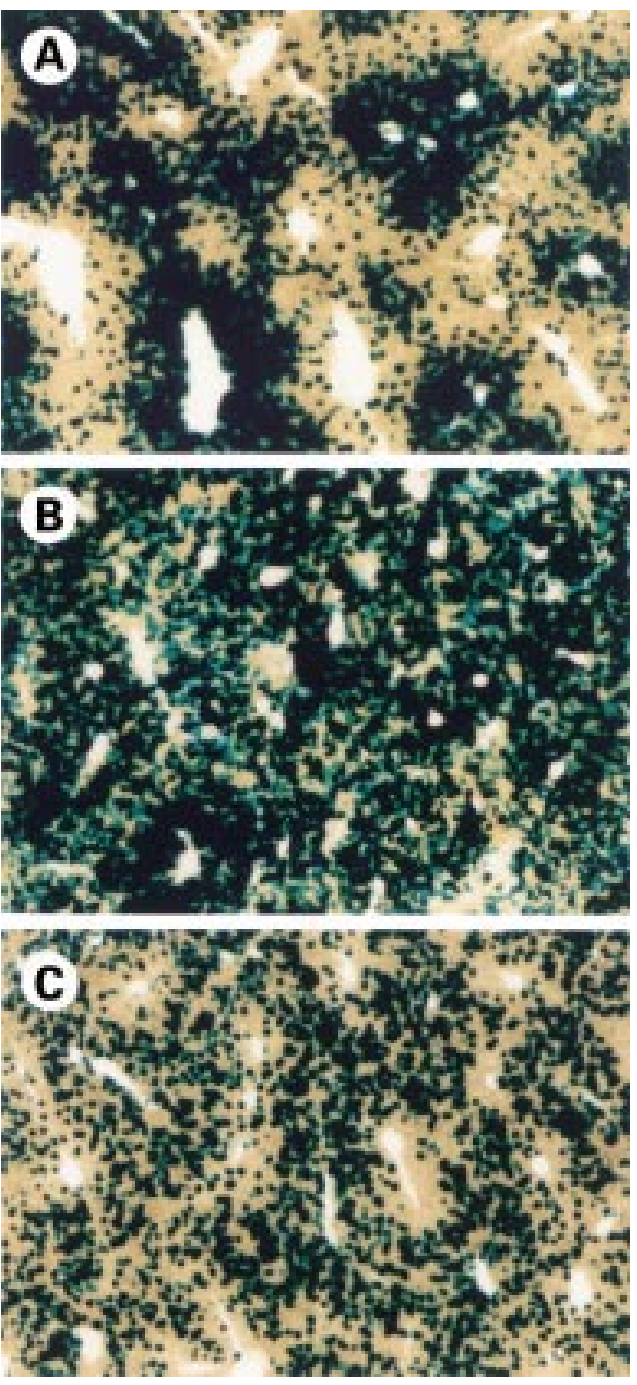

Figure 2 LacZ gene expression in the liver by intravenous administration of adenoviruses. Mice with normal, cirrhotic, and fulminant hepatitis livers were infused intravenously with adenoviruses $\left(2 \times 10^{8} \mathrm{pfu} / 200 \mu \mathrm{l}\right)$ carrying the lac $Z$ gene. Animals were killed on day 4 after adenoviral infusion and lac $Z$ gene expression was examined by X-gal staining. Approximately $40 \%, 80 \%$, and $40 \%$ of the whole liver was stained blue in the normal $(A)$, cirrhotic $(B)$, and fulminant hepatitis (C) livers, respectively.

(Original magnification $\times 40$.)

by an increase and thickening of the fibrotic septa, traversing the lobular parenchyma by portovenous or portoporto bridging, thus promoting the formation of pseudolobuli (fig 1B).

lacZ GENE EXPRESSION IN THE LIVER

We first confirmed that no X-gal staining positive cells were observed in normal livers or in severely damaged livers of animals that were not given intravenous infusion of adenoviruses. Based on our previous study, ${ }^{24}{ }^{25}$ we determined that peak lac $Z$ gene expression in the liver induced by intravenous administration of recombinant adenoviruses occurred 2-7 days after administration. Therefore, we examined lac $Z$ gene expression in normal and severely damaged livers of animals infused intravenously with $2 \times 10^{8} \mathrm{pfu}$ of adenoviruses four days after infusion. Although it is difficult to accurately estimate the rate of cells expressing the lac $Z$ gene in the liver, morphometric evalu-

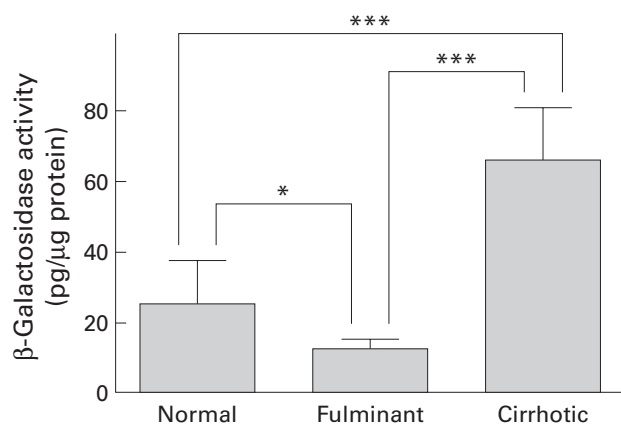

Figure 3 Quantitative estimation of lacZ expression in the liver by intravenous administration of adenoviruses. Mice with normal, cirrhotic, and fulminant hepatitis livers were infused intravenously with adenoviruses $\left(2 \times 10^{8}\right.$ pfu/200 $\left.\mu \mathrm{l}\right)$ carrying the lac $Z$ gene. Animals were killed on day 4 after adenoviral infusion and lac $Z$ gene expression was quantitatively estimated using the chemiluminescent reporter gene assay system. Each group consisted of eight animals. ${ }^{\star} 0.01<p<0.05,{ }^{*} * p<0.001$.

ation of liver sections using the public domain NIH Image program (written by Wayne Rasband at the National Institutes of Health, Bethesda, Maryland, USA) revealed that approximately $40 \%$ of cells in normal livers expressed the $l a c Z$ gene (fig $2 \mathrm{~A}$ ). X-gal staining positive cells were seen predominantly at periportal areas, the so-called Rappaport's zone 1, while a few positive cells were seen at centrilobular areas, the so-called zone 3. X-gal staining of cirrhotic livers induced by TAA revealed that X-gal staining positive cells occupied much larger areas of the liver compared with the normal liver, and that approximately $80 \%$ of cells in cirrhotic livers expressed the lac $Z$ gene (fig $2 \mathrm{~B}$ ). Although positive cells were densely seen in zone 1 , they spread from zone 1 to zone 2 and a considerable number of positive cells were also seen at zone 3 . Histochemical analysis of fulminant hepatitis livers induced by GalN and LPS revealed that approximately $40 \%$ of liver areas were stained blue with $\mathrm{X}$-gal staining (fig 2C). In contrast with the result of normal livers, X-gal staining positive cells were seen diffusely throughout fulminant hepatitis livers.

To quantitatively estimate levels of adenovirus mediated transgene expression in normal and severely damaged livers, livers were homogenised and $\beta$-galactosidase activity of the homogenates was measured using the chemiluminescent reporter gene assay system. Recombinant adenoviruses carrying the lac $Z$ gene $\left(2 \times 10^{8} \mathrm{pfu} / 200 \mu \mathrm{l}\right)$ were infused into the tail vein of mice. Livers were removed from animals four days after adenoviral infusion and $\beta$-galactosidase activity was measured. As shown in fig $3, \beta$-galactosidase activity of normal livers was 25.0 (12.7) pg of $\beta$-galactosidase/ $\mu$ g protein. Although lacZ gene expression in fulminant hepatitis livers was significantly lower than that in normal livers, marked levels of $\beta$-galactosidase activity were detected even in fulminant hepatitis livers, with values of 11.8 (3.6) $\mathrm{pg}$ of $\beta$-galactosidase/ $\mu \mathrm{g}$ protein. Conversely, lac $Z$ gene expression in cirrhotic livers was significantly higher than that in normal livers, with $\beta$-galactosidase 
Table 1 Serum biochemical data in normal, cirrhotic, and fulminant hepatitis livers, before and after infusion of adenovirus

\begin{tabular}{llll}
\hline Adenovirus infusion & Normal & Cirrhotic & Fulminant \\
\hline AST (u/litre) & & & \\
$\quad$ Before & $68.8(10.9)$ & $124.0(33.40)$ & $3311.7(1313.7)$ \\
After & $156.1(58.7)^{\star}$ & $260.1(91.2)^{\star}$ & $159.3(72.3)^{\star}$ \\
$\quad$ None & ND & ND & $177.9(67.0)^{\star}$ \\
ALT (u/litre) & & & \\
$\quad$ Before & $24.3(4.2)$ & $51.0(16.1)$ & $4469.0(1737.6)$ \\
After & $30.7(10.0)$ & $84.0(25.8)^{\star}$ & $47.3(38.8)^{\star}$ \\
None & ND & ND & $87.0(40.1)^{\star}$ \\
LD (u/litre) & $724.8(252.5)$ & $712.3(281.3)$ & $9094.7(2857.9)$ \\
Before & $2045.0(331.9)^{\star}$ & $1624.1(528.7)^{\star}$ & $1660.3(836.7)^{\star}$ \\
After & ND & ND & $1441.3(916.8)^{\star}$ \\
None & & &
\end{tabular}

*Data are mean (SD) of eight animals.

ALT, alanine aminotransferase; AST, aspartate aminotransferase; $\mathrm{LDH}$, lactate dehydrogenase, all expressed as units per litre at $37^{\circ} \mathrm{C}$.

${ }^{\star}$ Significantly different $(\mathrm{p}<0.05)$ from before administration of adenovirus, using Welch's $t$ test. $\mathrm{ND}$, not done.

activity being 66.0 (15.0) pg of $\beta$-galactosidase/ $\mu \mathrm{g}$ protein.

CYTOPATHIC EFFECTS OF ADENOVIRAL ADMINISTRATION INTO NORMAL AND DAMAGED LIVERS

Although it has already been shown that intraportal or intravenous administration of adenoviruses provokes inflammation of the liver, ${ }^{322}{ }^{25}$ the safety of adenoviral administration into animals with damaged livers remains to be examined. We infused $2 \times 10^{8} \mathrm{pfu}$ of adenoviruses intravenously into mice with normal livers and also those with severely damaged livers. There were no treatment related deaths. We examined liver related serum biochemical parameters, such as ALT, AST, and LDH, before and four days after adenoviral administration. As shown in table 1 , although serum levels of AST, ALT, and $\mathrm{LDH}$ increased after adenoviral administration in mice with normal livers and also in those with cirrhotic livers, the

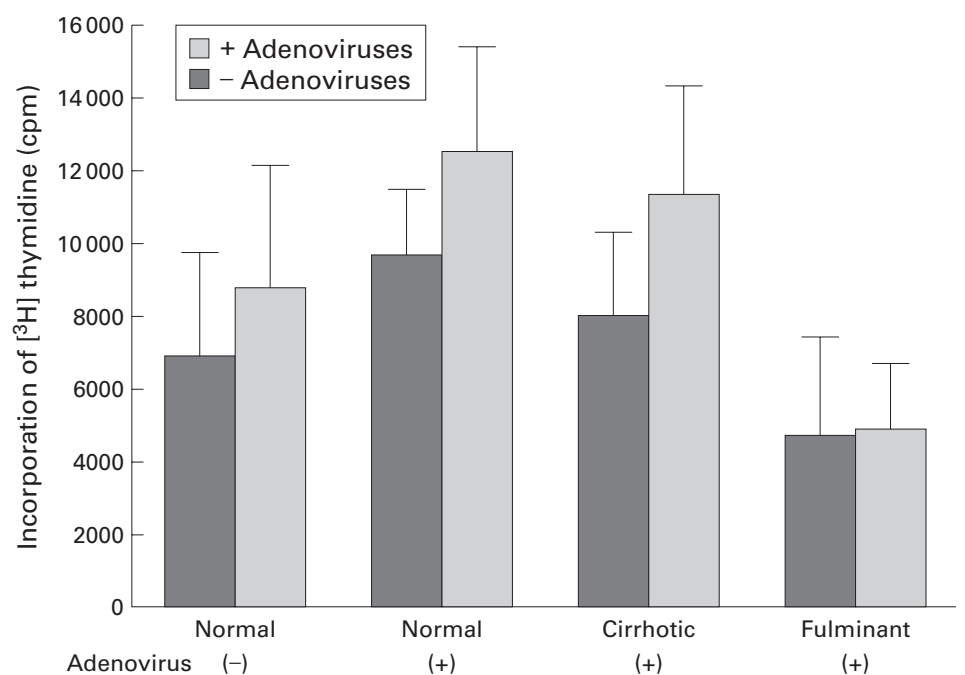

Figure 4 Cellular immune responses to adenoviral administration. To examine cellular immune responses to intravenous administration of adenoviruses, splenic cells were collected not only from naive mice that had normal livers and were not given the adenoviral infusion but also from mice with normal, cirrhotic, or fulminant hepatitis livers and given adenoviral infusion. Splenic cells were incubated with or without heat inactivated adenoviruses for five days and pulsed with [ $\left.{ }^{\beta} \mathrm{H}\right]$ thymidine for the last 18 hours of incubation. Each bar represents the mean (SD) of eight animals. There were no significant differences in proliferation of splenic cells between adenovirus stimulated and unstimulated cells in all groups. There were also no significant differences in proliferation among adenovirus stimulated splenic cells collected from naive mice and adenovirus treated mice with normal, cirrhotic, and fulminant hepatitis livers. increase was not marked. Serum levels of AST, ALT, and LDH increased only 2.3-, 1.3- and 2.8 -fold, respectively, in mice with normal livers, and only 2.1-, 1.6-, and 2.3-fold, respectively, in mice with cirrhotic livers. Conversely, serum levels of AST, ALT, and LDH decreased markedly in mice with fulminant hepatitis livers five days after treatment with GalN and LPS, regardless of adenoviral infusion, because of the lack of acute severe inflammation. Serum levels of AST, ALT, and LDH were not significantly different between mice with fulminant hepatitis livers treated with and without intravenous infusion of adenoviruses. Other liver related serum biochemical parameters, such as total bilirubin, albumin, alkaline phosphatase and choline esterase, as well as non-liver related parameters, such as creatinine and BUN, were not significantly different in mice with normal or cirrhotic livers before and after adenoviral infusion (data not shown). These parameters were not significantly different in mice with fulminant hepatitis livers treated with and without adenoviral infusion (data not shown).

We then examined if intravenous infusion of $2 \times 10^{8}$ pfu of adenoviruses into mice caused cytopathic effects in the liver. Histological analysis of normal livers revealed mild hepatitis-like pathological changes, such as hyperplastic changes in hepatocytes and infiltration of inflammatory cells. However, additional cytopathic effects caused by adenoviral infusion were not evident in cirrhotic livers due to the pre-existing inflammation (data not shown). Furthermore, consistent with the results of liver related biochemical parameters, severe inflammatory changes in fulminant hepatitis livers were absent regardless of the adenoviral infusion (data not shown). Although weak $l a c Z$ expression was detected by $\mathrm{X}$-gal staining in the kidney, cytopathic effects were not observed histologically in the kidney of mice with normal or severely damaged livers (data not shown).

CELLULAR IMMUNE RESPONSE TO ADENOVIRUS To examine cellular immune responses to adenovirus in mice with normal and severely damaged livers, activation of adenovirus specific splenic $\mathrm{T}$ cell proliferation was examined. Splenic cells collected from mice in the above experiments were incubated with heat inactivated adenoviruses which provides conditions that favour stimulation of $\mathrm{CD}^{+} \mathrm{T}$ cells as inactivated viral particles are processed by antigen presenting cells through the exogenous pathway of presentation, resulting in expression of viral peptides in association with MHC class II. ${ }^{21}$ As shown in fig 4, splenic cells collected from naive mice that had normal livers and did not receive intravenous infusion of adenoviruses did not proliferate significantly with stimulation with heat inactivated adenoviruses. Also, there were no significant differences in proliferation between adenovirus stimulated and unstimulated splenic cells collected from adenovirus injected mice with normal, cirrhotic, or fulminant hepatitis livers. Proliferation of splenic cells stimulated with 


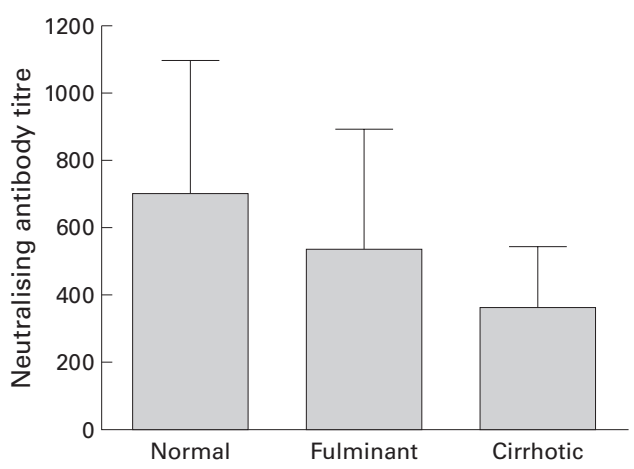

Figure 5 Humoral immune responses to adenoviral administration. To examine the development of neutralising antibodies against adenoviruses, serum samples collected from mice with normal, cirrhotic, and fulminant hepatitis livers were decomplemented, serially diluted, and analysed for neutralising antibodies against adenovirus serotype 5 . The titre of neutralising antibody for each sample is expressed as the reciprocal dilution of serum that inhibited adenoviral infection by 50\%. Each bar represents the mean (SD) of eight animals. There were no significant differences in titres of neutralising antibodies between groups.

heat inactivated adenoviruses was not significantly different between animals with normal, cirrhotic, and fulminant hepatitis livers.

HUMORAL IMMUNE RESPONSE TO ADENOVIRUS To examine humoral immune responses to adenovirus in mice with normal and severely damaged livers, serum samples were collected from mice in the above experiments and development of neutralising antibodies against adenovirus was examined. As shown in fig 5, mean titres of neutralising antibodies in animals with normal, cirrhotic, and fulminant hepatitis livers were $\times 700, \times 540$, and $\times 360$, respectively, on day 4 after adenoviral infusion. Although the titre was lower in animals with damaged livers than in those with normal livers, the differences were not statistically significant.

\section{Discussion}

The feasibility of gene therapy for hepatocellular carcinoma (HCC) has been intensively investigated $^{26-36}$ and HCC specific transgene expression was shown to be achievable by adenoviral vectors carrying an exogenous gene under the transcriptional control of the $\alpha$ fetoprotein gene promoter. ${ }^{37-39}$ However, it should be emphasised that only a minority of HCCs arises de novo in non-cirrhotic livers and in the majority of cases HCC is found in conjunction with liver cirrhosis. ${ }^{40}$ Therefore, the efficiency and safety of adenovirus mediated gene transfer into cirrhotic livers but not into normal livers need to be estimated before gene therapy with adenoviruses is used clinically for the treatment of HCC. We have demonstrated that adenovirus mediated gene transfer can be performed efficiently and safely, even in cirrhotic livers. Furthermore, transduction efficiency of the reporter $l a c Z$ gene was shown to be higher in cirrhotic than in normal livers. Transgene expression was observed almost throughout the cirrhotic liver, while it was restricted mainly to zone 1 in the normal liver. Although the reason for the difference in transgene expression pattern remains unknown, a plausible explanation is that these phenomena occur as a result of differences in portal flow velocity. It is well known that the liver is supplied with blood mainly from the portal vein but not from the hepatic artery. Therefore, it is thought that the majority of adenoviruses infused intravenously reach the liver by way of the portal vein. It was shown that portal flow velocity was significantly decreased in patients with liver cirrhosis, ${ }^{41}$ and also that forward/backward flow of the portal blood was observed in cirrhotic patients due to a thrombus blood clot of the portal vein. ${ }^{42}$ Castell and colleagues ${ }^{43}$ have shown that increasing the exposure time to adenoviruses provided a greater transduction efficiency in vitro. Taken together, these findings suggest that slow portal flow velocity carries adenoviruses more slowly from zone 1 to zone 3 through hepatic sinuses in cirrhotic livers than in normal livers and increases the contact time of adenoviruses to hepatocytes, resulting in a higher transduction efficiency and a larger transduction area of foreign genes in cirrhotic livers than in normal livers. Another explanation for the greater adenovirus mediated transduction of the foreign gene in cirrhotic livers is structural differences in the liver. The normally radial liver cell alignment is destroyed and fibrotic septa transversing the lobular parenchyma are present in cirrhotic livers. These structural changes may provide more space for adenoviruses to migrate into the liver.

In contrast with our results, Nakamura and colleagues $^{44}$ have recently shown that adenovirus mediated transfer of the lac $Z$ gene was markedly reduced in cirrhotic livers compared with normal livers. Although the investigators hypothesised that intralobular haemodynamics were reduced by formation of shunts between portal and central veins, resulting in markedly less transduction efficiency of the gene in cirrhotic livers, the existence of portovenous shunts in the rat cirrhosis model was not examined. They infused $1.5 \times 10^{9}$ pfu of adenoviruses into the rat tail vein while we infused $2 \times 10^{8}$ pfu of adenoviruses into the mouse tail vein. Therefore, the discrepancy in results does not appear to be due to the amount of adenovirus injected intravenously. Although the reasons for the discrepancy remain unknown, the difference may be attributed to the animal models used. They created a liver cirrhosis model by injecting $\mathrm{CCl}_{4}$ intraperitoneally into rats while our model involved intraperitoneal injection of TAA into mice. Although Coxsackie/adenovirus receptors were shown to be highly expressed in the normal murine liver, ${ }^{45}$ little is known of expression of the receptors in murine and rat cirrhotic livers. Therefore, it will be important to perform further studies before drawing conclusions about the efficacy of adenovirus mediated gene transfer into the cirrhotic liver.

Fulminant hepatitis has a poor prognosis. Although liver transplantation has been shown to have an impact on survival, it is feasible in only a minority of patients because of the limited number of equipped hospitals, particularly 
in Southeast Asia where the incidence of the disease is the highest in the world. It is well known that regeneration of hepatocytes does not occur in fulminant hepatitis, resulting in acute liver failure. Therefore, gene therapy stimulating regeneration of hepatocytes, such as transfer of the gene encoding the receptor for hepatocyte growth factor into hepatocytes, may be a promising strategy for the treatment of fulminant hepatitis. However, for gene therapy in fulminant hepatitis to be a clinical reality, it is necessary to determine the safety and efficiency of the treatment because it has been shown that intravenous administration of adenoviruses causes liver injury. In the present study, we demonstrated that efficient gene transduction into fulminant hepatitis livers was achieved by intravenous administration of adenoviruses without any significantly additional liver damage. Although the transduction efficiency of the lac $Z$ gene into fulminant hepatitis livers by an adenoviral vector was lower than that in normal livers, considerable levels of transgene expression were observed. The reduced transduction efficiency in fulminant hepatitis livers appears reasonable because the number of parenchymal cells in fulminant hepatitis livers is much smaller than that in normal livers due to massive necrosis of the liver, resulting in a much smaller chance for adenoviruses to encounter hepatocytes. Interestingly, lac $Z$ gene transduced cells were seen diffusely in fulminant hepatitis livers while transduced cells were seen predominantly in zone 1 of normal livers. The difference in spread of X-gal staining positive cells may be due to structural differences. The normal hepatic structure is profoundly destroyed in fulminant hepatitis livers. This may result in varied migration of adenoviruses in fulminant hepatitis livers.

Adenoviruses are known to induce acute liver injury and elicit humoral and cellular immune responses. ${ }^{47}$ We also demonstrated previously that intraportal administration of adenoviruses resulted not only in development of neutralising antibodies against adenovirus but also in induction of adenovirus specific $\mathrm{T}$ cells in rats. ${ }^{25}$ In the present study, we showed that development of neutralising antibodies against adenovirus was not significantly different among animals with normal and severely damaged livers, and that adenovirus specific $T$ cells were not activated significantly in animals with normal or severely damaged livers. Although intravenous infusion of adenoviruses causes acute liver injury, such as hepatic necrosis with elevation of liver related biochemical parameters, the immediate inflammatory responses may be attributed to non-specific adenovirus immune responses, such as induction of various chemokines and subsequent activation of neutrophils, macrophages, and natural killer cells. ${ }^{48}$ We estimated cellular and humoral immune responses to adenovirus four days after adenoviral administration but this may be too early to estimate immune responses to adenovirus. Although peak adenovirus mediated transgene expression occurs 2-7 days after adenoviral administration, ${ }^{25}$ it is consid- ered that stronger immune responses to adenovirus may be induced later. Therefore, further analyses may be required to examine whether there are differences in immune responses to adenovirus between animals with normal and severely damaged livers.

In summary, we have demonstrated that intravenous administration of adenoviruses into animals with cirrhotic or fulminant hepatitis livers resulted in efficient transduction and expression of the foreign gene in the liver without causing significant additional liver damage. Our results suggest that gene therapy using adenoviruses may be a feasible and promising therapeutic approach for the treatment of various diseases, even in patients with severe liver diseases. This work was supported in part by a Grant-in-Aid for Scientific
Research (B-10470140) from the Japanese Ministry of EducaResearch (B-10470140) from the Japa
tion, Science, Sports, and Culture.

1 Strauss SE. The adenoviruses. Ginsberg HS, ed. The adenoviruses. New York: Plenum Press, 1984:451-96.

2 Rosenfeld MA, Yoshimura K, Trapnell BC, et al. In vivo transfer of the human cystic fibrosis transmembrane conductance regulator gene to the airway epithelium. Cell 1992;68:143-55.

3 Zabner J, Couture LA, Gregory RJ, et al. Adenovirusmediated gene transfer transiently corrects the chloride transport defect in nasal epithelia of patients with cystic fibrosis. Cell 1993;75:207-16.

4 Crystal RG, McElvaney NG, Rosenfeld MA, et al. Administration of an adenovirus containing the human CFTR cDNA to the respiratory tract of individuals with cystic fibrosis. Nat Genet 1994;8:42-51.

5 Stratford-Perricaudet LD, Levrero M, Chasse JF, et al. Evaluation of the transfer and expression in mice of an evaluation of the transfer and expression in mice of an Hum Gene Ther 1990;1:241-56.

6 Jaffe H, Danel C, Longenecker G, et al. Adenovirusmediated in vivo gene transfer and expression in normal rat liver. Nat Genet 1992;1:372-8.

7 Kay MA, Landen CN, Rothenberg SR, et al. In vivo hepatic gene therapy: complete albeit transient correction of factor IX deficiency in hemophilia B dogs. Proc Natl Acad Sci USA 1994;91:2353-7.

8 Ishibashi S, Brown MS, Goldstein JL, et al. Hypercholesterolemia in low density lipoprotein receptor knockout mice and its reversal by adenovirus-mediated gene delivery. $\mathcal{F}$ Clin Invest 1993;92:883-93.

9 Kozarsky KF, McKinley DR, Austin LL, et al. In vivo correction of low density lipoprotein receptor deficiency in the Watanabe Heritable hyperlipidemic rabbit with recombinant adenoviruses. F Biol Chem 1994;269:13695-702.

10 Pinkert CA, Ornitz DM, Brinster RL, et al. An albumin enhancer located $10 \mathrm{~kb}$ upstream functions along with its promoter to direct efficient, liver-specific expression in promoter to direct efficient, liver-specific
transgenic mice. Gene Dev 1987;1:268-76.

11 Kuriyama S, Yoshikawa M, Ishizaka S, et al. A potential approach for gene therapy targeting hepatoma using a iver-specific promoter on a retroviral vector. Cell Struct Funct 1991;16:503-10.

12 Crystal RG. Transfer of genes to humans: early lessons and obstacles to success. Science 1995;270:404-10

13 Sullivan DE, Dash S, Du H, et al. Liver-directed gene transfer in non-human primates. Hum Gene Ther 1997;8:1195206.

14 Nakamura Y, Wakimoto H, Abe J, et al. Adoptive immunotherapy with murine tumor-specific $\mathrm{T}$ lymphocytes engineered to secrete interleukin 2. Cancer Res 1994;54:575760 .

15 Niwa H, Yamamura K, Miyazaki J, et al. Efficient selection for high-expression transfectants with a novel eukaryotic for high-expression transfectants

16 Miyake S, Makimura M, Kanegae Y, et al. Efficient generation of recombinant adenoviruses using adenovirus DNAterminal protein complex and a cosmid bearing the full-length virus genome. Proc Natl Acad Sci USA 1996;93: 1320-4.

17 Graham FL, Prevec L. Manipulation of adenovirus vectors. In: Murray EJ, ed. Methods in molecular biology. Clifton: Humana Press, 1991:109-28.

18 Decker K, Keppler D. Galactosamine hepatitis: key role of the nucleotide deficiency period in the pathogenesis of cell njury and cell death. Rev Physiol Biochem Pharmacol 1974; 71:77-105.

19 Galanos C, Freudenberg MA, Rertter W. Galactosamineinduced sensitization to the lethal effects of endotoxin. Proc Natl Acad Sci USA 1979:76:5939-43.

20 Chojkier M, Fierer J. D-Galactosamine hepatotoxicity is associated with endotoxin sensitivity and mediated by lymphoreticular cells in mice. Gastroenterology 1985;88:115- 
21 Kaplan JM, Smith AE. Transient immunosuppression with deoxyspergualin improves longevity of transgene expresmouse lung. Hum Gene Ther 1997;8:1095-104.

22 Kuriyama S, Tominaga K, Mitoro A, et al. Immunomodulation with FK506 around the time of intravenous readministration of an adenoviral vector facilitates gene transfer into primed rat liver. Int $\mathcal{F}$ Cancer 2000;85:839-44

23 Yang Y, Greenough K, Wilson JM. Transient immune blockade prevents formation of neutralizing antibody to recombinant adenovirus and allows repeated gene transfer to mouse liver. Gene Ther 1996;3:412-20.

24 Kuriyama S, Tominaga K, Kikukawa $\mathrm{M}$, et al. Inhibitory effects of human sera on adenovirus-mediated gene transfer into rat liver. Anticancer Res 1998;18:2345-52.

25 Kuriyama S, Tominaga K, Kikukawa M, et al. Transient cyclophosphamide treatment before intraportal readministration of an adenoviral vector can induce re-expression of the original gene construct in rat liver. Gene Ther 1999;6:749-57.

26 Kuriyama S, Yoshikawa M, Tominaga K, et al. Gene therapy for the treatment of hepatoma by retroviral-mediated gene
transfer of the herpes simplex virus thymidine kinase. Int transfer of the herpes simplex
Hepatol Commun 1993;1:253-9.

27 Kuriyama S, Nakatani T, Masui K, et al. Bystander effect caused by suicide gene expression indicates the feasibility of gene therapy for hepatocellular carcinoma. Hepatology 1995;22:1838-46.

28 Kuriyama S, Nakatani T, Masui K, et al. Evaluation of prodrugs ability to induce effective ablation of cells transduced with viral thymidine kinase gene. Anticancer Res 1996;16: 2623-8.

29 Kuriyama S, Sakamoto T, Masui K, et al. Tissue-specific expression of HSV-tk gene can induce efficient antitumor expect and protective immunity to wild-type hepatocellular carcinoma. Int $\mathcal{F}$ Cancer 1997;71:470-5.

30 Kuriyama S, Masui K, Kikukawa M, et al. Complete cure of established murine hepatocellular carcinoma is achievable by repeated injections of retroviruses carrying the herpes by repeated injections of retroviruses carrying the herpes 525-33.

31 Kuriyama S, Kikukawa M, Masui K, et al. Cytosine deaminase/5-fluorocytosine gene therapy can induce efficient anti-tumor effects and protective immunity in immunocompetent mice but not in athymic nude mice. In f Cancer 1999;81:592-7.

32 Kuriyama S, Kikukawa M, Masui K, et al. Cancer gene therapy with HSV-tk/GCV system depends on T-cellmediated immune responses and causes apoptotic death of tumor cells in vivo. Int f Cancer 1999;83:374-80.

33 Kuriyama S, Mitoro A, Yamazaki M, et al. Comparison of gene therapy with the herpes simplex virus thymidine kinase gene and the bacterial cytosine deaminase gene for the treatment of hepatocellular carcinoma. Scand f Gastroenterol 1999;34:1033-41.
34 Cao G, Kuriyama S, Du P, et al. Construction of retroviral vectors to induce strong hepatoma cell-specific expression 35 Cao G, Kuriyama S, Du P, et al. Complete regression of established murine hepatocellular carcinoma by in vivo tumor necrosis factor $\alpha$ gene transfer. Gastroenterology 1997;112:501-10

36 Cao G, Kuriyama S, Tsujinoue $\mathrm{H}$, et al. A novel approach for inducing enhanced and selective transgene expression in hepatocellular carcinoma cells. Int f Cancer 2000;87: $247-52$.

37 Kanai F, Lan KH, Shiratori Y, et al. In vivo gene therapy for $\alpha$-fetoprotein-producing hepatocellular carcinoma by adenovirus-mediated transfer of cytosine deaminase gene. Cancer Res 1997;57:461-5.

38 Kanai F, Shiratori Y, Yoshida Y, et al. Gene therapy for $\alpha$-fetoprotein-producing human hepatoma cells by adenovirus-mediated transfer of the herpes simplex virus thymidine kinase gene. Hepatology 1996;23:1359-68.

39 Kaneko S, Hallenbeck P, Kotani T, et al. Adenovirusmediated gene therapy of hepatocellular carcinoma using mediated gene therapy of hepatocellular carcinoma using

40 Brotodihardjo AE, Tait N, Weltman MD, et al. Hepatocellular carcinoma in western Sydney: aetiology, changes in incidence, and opportunities for better outcomes. Med $\mathcal{F}$ incidence, and opportuni

41 Chawla Y, Santa N, Dhiman RK, et al. Portal hemodynamics by duplex Doppler sonography in different grades of cirrhosis. Dig Dis Sci 1998;43:354-7.

42 Furuse J, Matsutani S, Yoshikawa M, et al. Diagnosis of poral vein tumor thrombus by pulsed Doppler ultrasonography. F Clin Ultrasound 1994;171:1097-104.

43 Castell JV, Hernández D, Gómez-Foix AM, et al. Adenovirus-mediated gene transfer into human hepatocytes: analysis of the biochemical functionality of transduced cells. Gene Ther 1997;4:455-64.

44 Nakamura T, Akiyoshi H, Saito I, et al. Adenovirusmediated gene expression in the septal cells of cirrhotic rat mediated gene expression in the

45 Bergelson JM, Krithivas A, Celi L, et al. The murine CAR homolog is a receptor for coxsackie $B$ viruses and adenoviruses. F Virol 1998;72:415-19.

46 Huard J, Lochmuller H, Acsadi G, et al. Differential shortterm transduction efficiency of adult versus newborn mouse tissues by adenoviral recombinants. Exp Mol Pathol 1995;62:131-43.

47 Dai Y, Schwarz EM, Gu D, et al. Cellular and humoral immune responses to adenoviral vectors containing factor IX gene: tolerization of factor IX and vector antigens allows for long-term expression. Proc Natl Acad Sci USA 1995;92: 1401-5

48 Muruve DA, Barnes MJ, Stillman IE, et al. Adenoviral gene therapy leads to rapid induction of multiple chemokines and acute neutrophil-dependent hepatic injury in vivo. Hum Gene Ther 1999;10:965-76. 